\author{
Military Technical College \\ Kobry El-Kobbah, \\ Cairo, Egypt
}

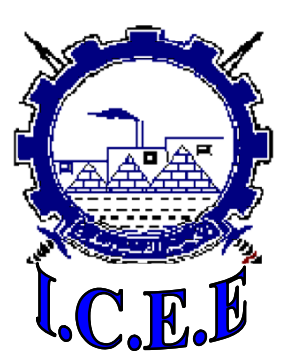

NBC-3

\author{
$5^{\text {th }}$ International Conference
}

on

Chemical \& Environmental

Engineering

25 - 27 May, 2010.

NBC Protection

\title{
PRINCIPLE OF BIOLOGICAL WARFARE PROTECTION
}

\author{
Hytham A. El Hadidy*
}

\begin{abstract}
Although the deliberate of disease as a weapon, against humans animals or plants is totally prohibited by BTWC which entered into force in 1975, the danger that biological weapons may be used by rogue states or terrorists groups is recognized as presenting the greatest danger of all weapons of mass destruction (NCB). Detection technology rests on basic knowledge and research in aerobiology of particular important are studies concerning collection of organisms and sampling devices. few of the possible practical approaches will be described briefly. As already pointed out, the requirements of detection, early warning and rapid identification are closely related aspects of defense against attack with biological agents.
\end{abstract}

\footnotetext{
*Egyption Armed Forces
} 